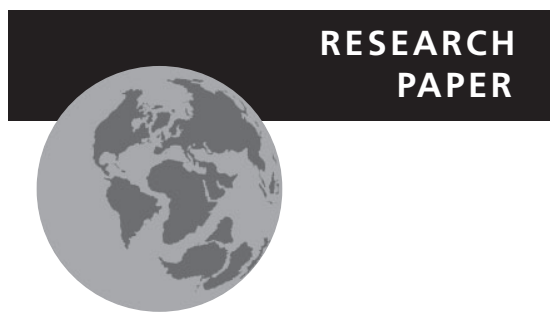

\title{
How do islands become green?
}

\author{
Ruben Heleno ${ }^{1 \star}$ and Pablo Vargas ${ }^{2}$
}

${ }^{1}$ Centre for Functional Ecology, Department of Life Sciences, University of Coimbra, Coimbra, Portugal, ${ }^{2}$ Real Jardín Botánico de Madrid (CSIC-RJB), Madrid, Spain
${ }^{*}$ Correspondence: Ruben H. Heleno, Centre for Functional Ecology, Department of Life Sciences, University of Coimbra, Calçada Martim de Freitas, 3000-456 Coimbra, Portugal. E-mail: rheleno@uc.pt

\section{ABSTRACT}

Aim Four long-distance dispersal (LDD) modes have generally been considered to play central roles in the colonization of islands by plants: anemochory (dispersal by wind), thalassochory (dispersal by oceanic currents), endozoochory (internal dispersal by animals) and epizoochory (external dispersal by animals). However, seeds can also be transported by vectors different from those to which they are best suited (non-standard dispersal), meaning that the actual vector of colonization cannot be inferred based on diaspore traits alone. We propose an alternative approach to explore the relative contribution of LDD syndromes to island colonization.

Location Europe and the Azores.

Methods We scored the presence of syndromes relevant for LDD in the native flora of Europe (c. 10,000 species) and the Azores (148 species). We then contrasted the importance of each syndrome in the recipient flora (Azores) and the source floras (Europe and mainland Portugal) to estimate which, if any, syndrome was particularly successful for overseas colonization. We further investigated whether particular LDD syndromes increased plant distribution within the Azores archipelago.

Results Most native species in Europe (63\%), mainland Portugal (67\%) and the Azores (63\%) produce unspecialized diaspores. Only species adapted to sea dispersal were overrepresented in the Azores, while those adapted to wind dispersal were underrepresented. The presence of LDD syndromes did not significantly improve the distribution of plant species across the archipelago, except for the moderate advantage of endozoochorous diaspores. Differences in the importance of LDD syndromes across plant families at least partially explain the floristic disharmony of the Azorean flora.

Main conclusions Only thalassochory appeared to have significantly favoured the colonization of the Azores. The high proportion of unspecialized diaspores, the unexceptional representation of most specialized LDD syndromes and the dissociation between syndromes and inter-island plant distribution in the Azores suggest that non-standard events are more common than previously believed in the colonization of islands by plants.

\section{Keywords}

Anemochory, Azores, endozoochory, epizoochory, LDD, oceanic islands, plant colonizations, seed dispersal syndromes, thalassochory, theory of island biogeography.

\section{INTRODUCTION}

How plants first arrived on originally lifeless islands in the middle of the oceans has intrigued naturalists for centuries (Darwin, 1859; Godman, 1870; Ridley, 1930). The dispersal of seeds and spores, and particularly long-distance dispersal (LDD), has been long identified as the key process by which plants can occupy new territories and is critical for the colonization of oceanic islands (Nathan, 2006; Traveset et al., 2014). However, the arrival of new diaspores (i.e. the reproductive 
structure that gets dispersed) to remote islands is so episodic (Schaefer et al., 2011a) that the relative importance of different modes of colonization cannot be experimentally observed (Jordan, 2001; Higgins et al., 2003; Vargas et al., 2012).

Many seed plants have morphological adaptations that confer upon their diaspores special advantages for being transported by specific vectors. Four specific sets of diaspore traits can promote their long-distance dispersal (LDD syndromes): wings and plumes facilitate suspension in the wind (anemochory); low density and protective tissues promote floatability and protection of seeds in seawater currents (thalassochory); nutritive tissues attract frugivores that will disperse the seeds internally (endozoochory); and hooks, barbs and adhesive substances promote external adhesion to animals (epizoochory) (Fig. 1; see Appendix S1 in the Supporting Information for details) (Howe \& Smallwood, 1982; Van Der Pijl, 1982; Traveset et al., 2014). Such morphological specializations are commonly categorized into LDD syndromes according to the dispersal vectors to which they are particularly well adapted (Hughes et al., 1994), thus reflecting the process which is most likely to move the majority of seeds, i.e. the standard dispersal mechanism (sensu Higgins et al., 2003). Based on this information, naturalists have historically inferred the vectors responsible for island colonization by identifying the dispersal syndromes of insular floras (see Vargas et al., 2012). However, the presence of a particular LDD syndrome does not necessarily imply that it was responsible for the actual arrival of the propagules because diaspores can also be transported by alternative, i.e. non-standard, vectors (Higgins et al., 2003; Thomson et al., 2010). For instance, anemochorous seeds can be ingested and dispersed effectively by birds (Heleno et al., 2013); this makes direct inferences about mode of dispersal inevitably speculative (see Vargas et al., 2012). Alternatively, testing whether particular diaspore traits have been favourable for the formation of insular floras provides a more objective, evolutionary framework for exploring the success of particular diaspore types in LDD (Fig. 2).

By contrasting the full spectra of dispersal syndromes of insular floras against those of their continental source floras we can estimate which, if any, of these sets of traits have been particularly successful in promoting colonization (Jordan, 2001; Gillespie et al., 2012). The canonical hypothesis is that plants with LDD syndromes should be consistently over-represented in insular floras due to their advantage during colonization (Carlquist, 1966). Indeed, comparison of 187 angiosperm species shared between Tasmania and New Zealand suggested that coastal plants with very small seeds and hooked fruits are particularly advantageous for dispersal across the $c .1500 \mathrm{~km}$ of ocean between them (Jordan, 2001). The question remains as to whether species displaying any particular LDD syndromes have been favoured in the colonization of volcanic archipelagos by continental floras, and whether plants without specialized LDD syndromes were negatively selected, as predicted by theory (Carlquist, 1966).

The nine islands of the Azores in the North Atlantic, largely influenced by the European flora (Fig. 1), offer an unparalleled opportunity for evaluating the success of plant dispersal to and within the archipelago. Here we compare the full spectrum of LDD syndromes in the native Azorean flora and those of the source floras of Europe and mainland Portugal. These analyses are largely complementary because the European flora includes the most nearly related continental flora available for colonization of the Azores, while the subset formed by the mainland Portuguese flora represents a comparable territory in terms of habitat similarity, notably maximum elevation, latitude range, coastal length and climate. We specifically explored: (1) the relative representation of specialized and unspecialized LDD syndromes in the three floras; (2) which syndromes are more likely to have favoured the dispersal of diaspores from Europe and mainland Portugal to the Azores; (3) whether any particular
Figure 1 Map of Europe, mainland Portugal and the Azores $\left(37-40^{\circ} \mathrm{N}\right.$, $25-31^{\circ} \mathrm{W}$ ), representing the regions whose floras have been included in this study (shaded area). See Winter et al. (2009) and Tutin et al. (1980) for details on the geographic coverage of Flora Europaea. The insets show typical dispersal traits of the four long-distance dispersal syndrome classes considered in this study: endozoochorous (animal interior), epizoochorous (animal exterior), anemochorous (wind), thalassochorous (oceanic currents) and unspecialized diaspores (without specializations relevant for long-distance dispersal).

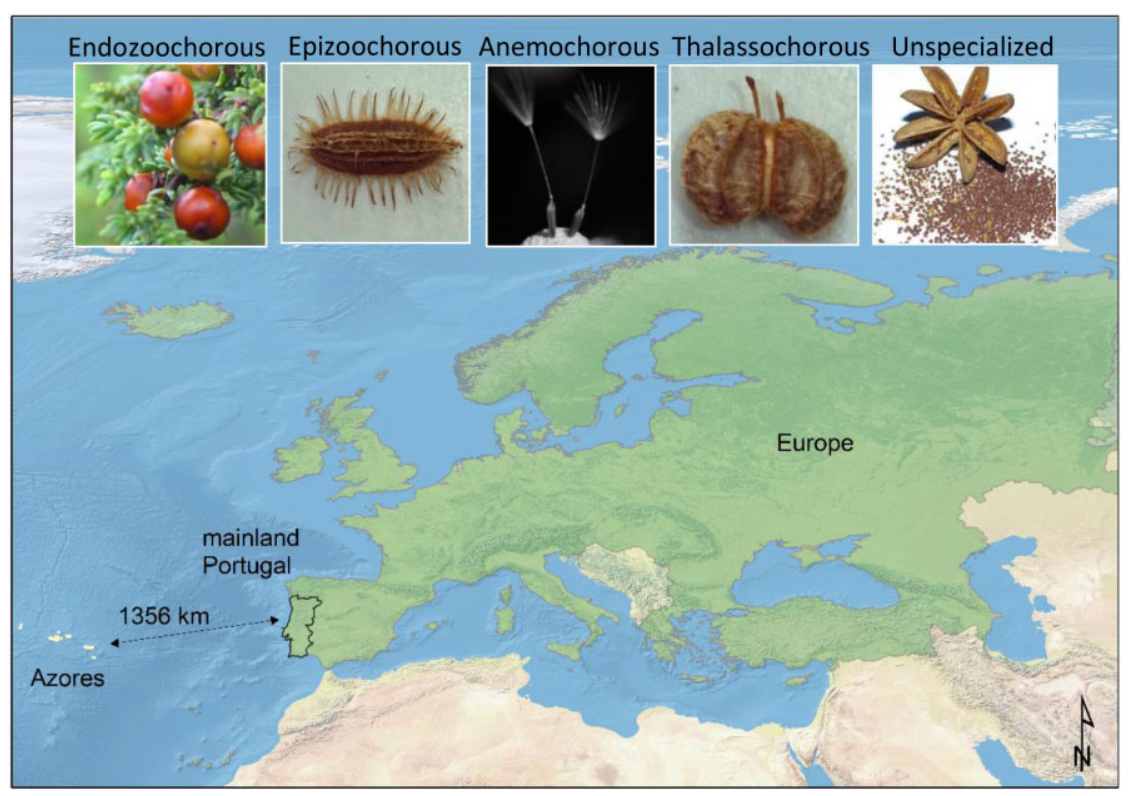




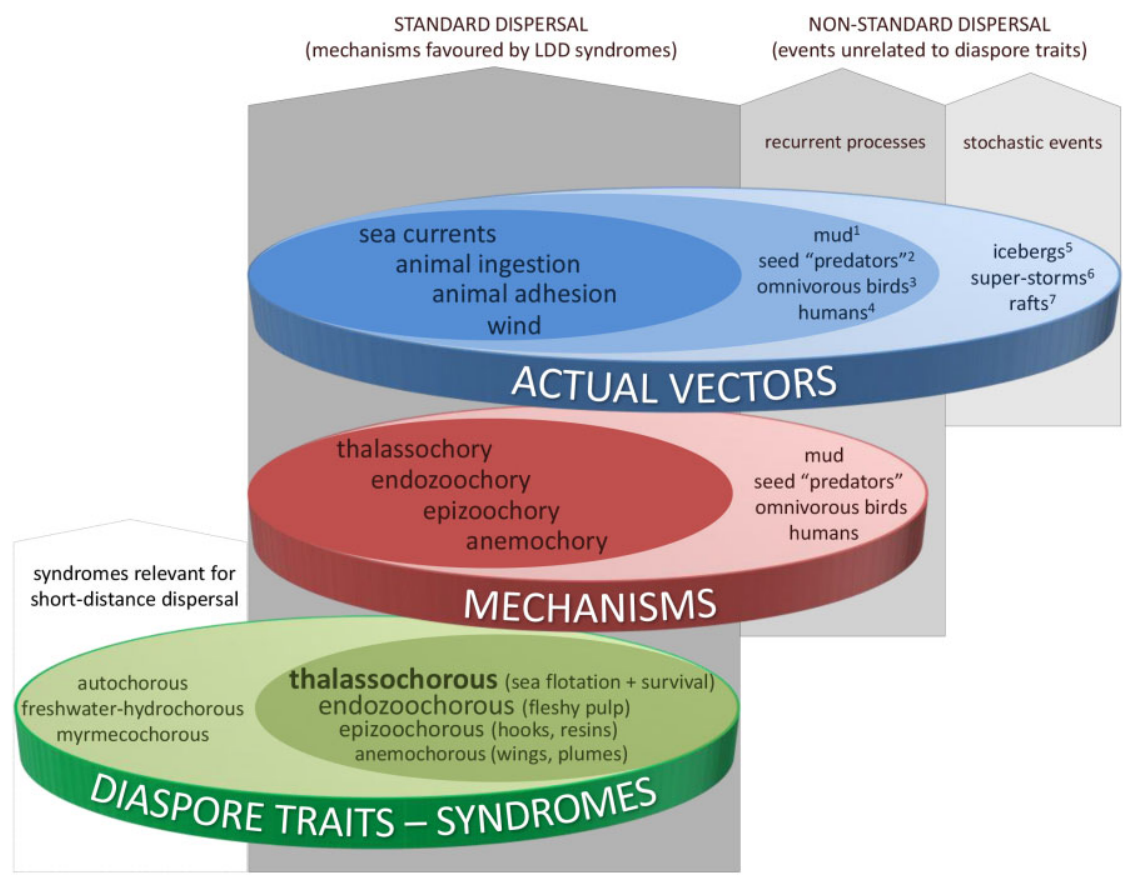

Figure 2 Conceptual diagram of the relationships between the three levels of information on long-distance dispersal of seeds (LDD) to the Azores. The estimated importance of each LDD syndrome to the colonization of the Azores (this study) is proportional to the font size of that syndrome in the bottom ring. References in the figure: ${ }^{1} \mathrm{Guppy}$ 1917, ${ }^{2}$ Heleno et al. 2011, ${ }^{3}$ Nogales et al. 2012, ${ }^{4}$ Silva et al. 2008, ${ }^{5}$ Darwin 1859 , ${ }^{6}$ Meireles et al. 2013, ${ }^{7}$ Ridley 1930. syndrome is associated with broader plant distributions across the islands of the archipelago; and (4) if a differential dispersal capacity of plants can explain insular floristic disharmony, as predicted by the theory of island biogeography (Carlquist, 1966; Macarthur \& Wilson, 1967; Gillespie, 2007).

\section{METHODS}

\section{The Azores and the European source floras}

The Azores archipelago, $1356 \mathrm{~km}$ west of continental Europe (Fig. 1), comprises nine recently formed (<8.12 Ma; Azevedo \& Ferreira, 2006) volcanic islands. The climate is markedly oceanic, with high relative humidity, mild temperature and high levels of cloud cover throughout the year (Climaat, 2013).

The native forest of the Azores -laurel forest - is broadly considered to be a relic of the southern European and North African forests of the late Tertiary (Vargas, 2007; Barrón et al., 2010; Fernandez-Palacios et al., 2011). For the Azorean spermatophyte flora, comprising 148 native species, about 30\% of which are endemic, and over 800 introduced species, we followed the checklist and chorology published by Schaefer et al. (2011a). The flora is largely considered to have colonized the Azores from continental Europe (Guppy, 1917; Dias, 2001; Schaefer, 2003; Fernandez-Palacios et al., 2011). The few exceptions are Myrsine retusa and Dracaena draco of African origin, Pericallis malvifolia of Canarian origin and Solidago sempervirens of American origin (Guppy, 1917; Panero et al., 1999; Fernandez-Palacios et al., 2011). Based on a recent palynological analysis, Illecebrum verticillatum is also considered native (Connor et al., 2012).

The lists of plant species native to Europe (10,792 species) and mainland Portugal (c. 2294 species) were retrieved from Flora
Europaea (Tutin et al., 1980), which includes the flora of 23 countries/regions (Fig. 1; Winter et al., 2009).

\section{Syndrome assignation}

All spermatophytes native to Europe or the Azores were characterized according to the presence of LDD syndromes. Assignment of the dispersal syndrome was based on diaspore morphology, classifying diaspores into five classes according to the presence/absence of morphological traits specialized to favour particular dispersal vectors (Tutin et al., 1980). This categorization intentionally excludes information on observed dispersal vectors, being restricted to diaspore traits that can provide an advantage for LDD. This is an important difference from other studies because it: (1) dispenses with the assumption of a direct causal relationship between diaspore traits and actual dispersal vectors; (2) does not require that all plants are categorized into specific and often fuzzy (e.g. mud dispersal) dispersal syndromes to account for their presence in insular floras; and (3) excludes dispersal syndromes limited to short distances (e.g. myrmecochory, autochory) that are irrelevant in the context of the colonization of remote islands. A detailed guide for the classification of LDD syndromes is included as Supporting Information (see Appendix S1) and can be summarized as follows. Information on diaspore traits relevant for LDD was initially compiled from seven large databases available online. The gathered information was cross-checked and completed/ corrected based on diaspore descriptions from the literature, consultation with experts on selected families (see Acknowledgements), study of herbarium specimens and personal experimentation (Appendix S1). Species were coded on the basis of their diaspore morphology into four LDD syndromes, i.e. traits that are considered to facilitate dispersal by specific LDD vectors 
on a biogeographic scale. Species that lacked specialized dispersal structures relevant for LDD were classified as 'unspecialized', reflecting exclusively a lack of specializations rather than a lack of information.

For species with multiple syndromes, their relative importance was weighted in order to reflect an a priori equal probability of each syndrome in assisting the LDD events and eventually island colonization (Appendix S2). Thus, in species with a single LDD syndrome that syndrome was assigned a value of 1 , and in species with multiple syndromes their individual weights were scored so that they summed up to 1 (see Whittaker et al., 1989; Vargas et al., 2012; Vargas et al., 2014). This weighting also suitably incorporates the probability that a seed travelled by multiple consecutive dispersal vectors (e.g. endozoochory followed by thalassochory).

\section{Statistical analyses}

Differences in the frequency distribution of syndromes between Europe and the Azores and mainland Portugal and the Azores were explored by checking if the proportion of plants of each syndrome class in the Azorean flora fell within the $95 \%$ confidence intervals of 1000 bootstrap replicates of insular floras of the same size $(n=148)$ randomly extracted from the two source floras. Overall differences in syndrome representation between Europe and the Azores and Portugal and the Azores were tested with likelihood ratio tests (G-tests).

The direction and strength of syndrome selectivity (a proxy of colonization effectiveness) was estimated using the ManlyChesson selectivity index (Chesson, 1978), reflecting the 'use of the syndrome' (i.e. successful colonization of the Azores) in relation to the 'availability' of the syndrome in the source floras. The index is equal to 1 if a syndrome is equally represented in both floras (no selection) and higher or lower than 1 if a syndrome is positively or negatively selected, respectively (Mittlebach, 2000).

The importance of the four syndromes for the colonization of islands within the archipelago was explored with two generalized linear models. A first analysis tested whether the presence of at least one LDD syndrome was associated with broader distributions of plant species throughout the archipelago measured as the number of islands where each species is present (Poisson distributed). A second analysis evaluated the effect of each individual syndrome on species distribution range (i.e. the number of islands occupied).

Differences between the number of species of all plant families present in mainland Portugal and the Azores (floristic disharmony) were evaluated with multiple likelihood ratio tests (G-tests) testing significance against a Bonferroni corrected $\alpha$.

\section{RESULTS}

The dispersal syndromes with potential for promoting longdistance dispersal on a biogeographic scale were identified for 10,358 plant species, including the complete native floras of the Azores and mainland Portugal, and $96.2 \%$ of the native flora of Europe. The remaining $3.8 \%$ of species were excluded from the analyses as we could not gather sufficient reliable information for a correct assignation of syndromes.

The majority of plant species on the three considered floras produced diaspores that were unspecialized with respect to the four LDD syndromes, namely Europe (62.8\%), mainland Portugal (67.0\%) and the Azores (62.8\%) (Table 1). The relative importance of the syndromes differed both between Europe and the Azores (overall test $G_{4}=14.2 ; P<0.001$ ) and between mainland Portugal and the Azores (overall test $G_{4}=10.1$; $P=0.04)$. Specifically, diaspore adaptations towards sea dispersal (thalassochory) were significantly more common in the Azores than in either Europe or mainland Portugal (Fig. 3a; Appendix S3). Adaptations to endozoochory were significantly more common in the Azores than in mainland Portugal. Finally, adaptations to wind dispersal (anemochory) were significantly less common in the Azores then in Europe (Fig. 3a).

Accordingly, the Manly-Chesson selectivity index revealed a strong positive discrimination $\left(\mathrm{M}-\mathrm{C}_{\text {selectivity }}\right.$ index $\left.>>1\right)$ of thalassochorous diaspores, a small but consistent positive discrimination of endozoochorous diaspores $\left(\mathrm{M}-\mathrm{C}_{\text {selectivity index }}>1\right)$ and negative discrimination of anemochorous diaspores

Table 1 Relative proportion (\%) of syndromes present in the flora of Europe, mainland Portugal and the Azores. Proportions of syndromes in the Galápagos (Vargas et al., 2012), Hawaii (Carlquist, 1974) and the Canary Islands (Arjona et al. unpublished), are shown here for comparison. The square brackets indicate the percentage of Hawaiian plant species with small, undifferentiated seeds growing near aquatic environments, assumed by Carlquist (1974) to be dispersed on mud attached to birds' feet.

\begin{tabular}{|c|c|c|c|c|c|c|}
\hline & Europe & Portugal & Azores & Galápagos & Hawaii & Canaries \\
\hline Endozoochory & 7.9 & 6.1 & 10.5 & 16 & 38.9 & 17 \\
\hline Epizoochory & 5.2 & 9.4 & 6.8 & 16 & 23.1 & 3.8 \\
\hline Thalassochory & 1.6 & 3.7 & 9.3 & 19 & 22.8 & 7.7 \\
\hline Anemochory & 22.5 & 13.7 & 10.6 & 13 & 1.4 & 24.3 \\
\hline Unspecialized diaspores & 62.8 & 67.0 & 62.8 & 36 & {$[12.8]$} & 47.3 \\
\hline Number of native species & 10792 & 2294 & 148 & c. 500 & c. 1000 & c. 1500 \\
\hline Distance to continent $(\mathrm{km})$ & - & - & 1356 & 972 & 3650 & 96 \\
\hline
\end{tabular}



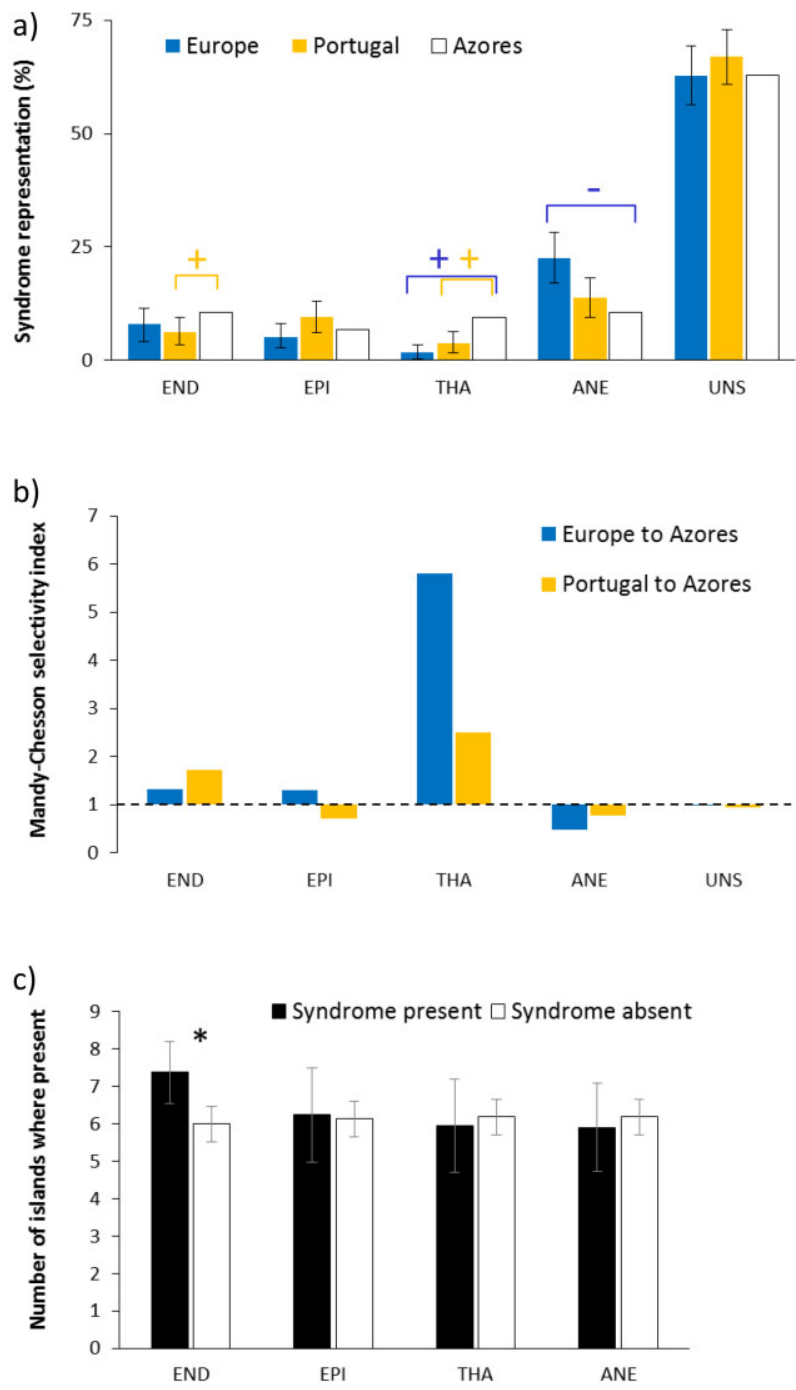

Figure 3 Contribution of the four long-distance dispersal syndromes for island colonization. END, endozoochorous; EPI, epizoochorous; THA, thalassochorous; ANE, anemochorous; UNS, unspecialized diaspores. (a) Frequency distribution of syndromes in the source floras of Europe and mainland Portugal versus the recipient Azorean flora. Error bars indicate the 95\% confidence intervals expected for the syndromes of the Azorean flora based on 1000 bootstrap replicates of virtual insular floras ( $n=148$ species) retrieved from the European and mainland Portugal floras. Observed syndrome frequencies outside the estimated confidence intervals (i.e. statistically significant to $\alpha=0.05$ ) are marked with '+' or '-', respectively, indicating overor underrepresentation of syndromes in the Azores. (b) The Manly-Chesson selectivity index $(\alpha)$ between the relative availability (Europe and mainland Portugal) and 'use' (Azores) of each syndrome class. Values higher than 1 indicate a positive selection and values lower than 1 indicate a negative selection of that syndrome. (c) Distribution of plants with and without each particular LDD syndrome across the nine Azorean islands (mean number of islands $\pm 95 \%$ confidence intervals). Statistically significant differences $(\alpha=0.05)$ are marked with an asterisk.
$\left(\mathrm{M}-\mathrm{C}_{\text {selectivity index }}<1\right.$; Figure $\left.3 \mathrm{~b}\right)$. Interestingly, while these results considered the syndromes of the entire Azorean flora, we found similar frequency distributions of LDD syndromes when contrasting the nine islands individually (Appendix S4).

Most native plant species were widely distributed across the archipelago (mean $\pm \mathrm{SD}=6.1 \pm 2.7$ islands; Appendix S5) (but see also Schaefer et al., 2011b, for the likely effect of some cryptic species on this pattern). We found that only specializations for internal dispersal by animals (fleshy diaspores) were significantly associated with broader plant distributions across the nine Azorean islands (mean distribution of nonendozoochorous plants $=6.0$ islands; endozoochorous plants $=7.4$ islands; Wald chi-square $=4.2 ; P=0.04$, Fig. $3 \mathrm{c}$ ). The other three LDD syndromes did not significantly affect plant distribution within the archipelago (Wald chisquare $<0.2 ; P>0.63$, Fig. $3 c)$.

The relative species richness of the Azorean plant families differed significantly from the relative richness of the European flora $\left(G_{47}=198 ; P<0.001\right)$. Individual comparisons revealed that 48 of the 142 European families were present in Azores. Eleven families were overrepresented and six were underrepresented in the insular flora $(P<0.05$; Appendix S6). After Bonferroni correction $\left(\alpha_{\text {corrected }}=0.00035\right)$, Cyperaceae, Juncaceae and Potamogetonaceae were significantly overrepresented and Asteraceae and Fabaceae were significantly underrepresented in the Azores (Appendix S6).

\section{DISCUSSION}

The relative importance of LDD syndromes in the native Azorean flora when compared with the source floras of Europe and mainland Portugal suggests that only traits related to sea dispersal have been clearly advantageous in the colonization of the archipelago. Previous research has already reported a large proportion of coastal and estuarine plants in the shared flora of Tasmania and New Zealand (Jordan, 2001). Here we compared for the first time the LDD syndromes of a whole continental source flora and that of a recipient remote archipelago of volcanic origin (i.e. originally sterile), and substantiated the importance of thalassochory for colonization.

The colonization of oceanic islands is likely to involve a combination of deterministic (i.e. standard) and alternative (non-standard) dispersal mechanisms (Nogales et al., 2012; Fig. 2). Nevertheless, a growing body of knowledge suggests that the role of non-standard dispersal during island colonization may be more important than historically appreciated. Specifically: (1) plants with unspecialized LDD diaspores are highly and equally common in the European and Azorean floras, suggesting that their dispersal has not been significantly limited by the large oceanic barrier; (2) plants with LDD syndromes predicted to promote island colonization are not consistently overrepresented in the Azores; (3) most native plants in the Azores are widely distributed across the archipelago despite many having non-specialized diaspores; and (4) most LDD syndromes did not seem to improve dispersibility of plants across the archipelago, with the exception of the 
significant but still small effect of endozoochorous diaspores (see also Vargas et al., 2014). Furthermore, current evidence suggests that the relative importance of the predominant dispersal syndromes is highly idiosyncratic across insular floras: endozoochory seems to be common in Hawaii (Carlquist, 1974), anemochorous plants prevail in the Canary Islands (Arjona et al. unpublished), thalassochorous plants are predominant in the Galápagos (Vargas et al., 2012) (Table 1) and the relative importance of different syndromes alternated through time in Krakatau (Whittaker \& Fernández-Palacios, 2007). Such idiosyncrasy suggests that no single syndrome stands out as ubiquitously important for the colonization of remote islands, with the potential exceptions of thalassochory (Whittaker et al., 1989; Vargas et al., 2012; Vargas et al., 2014; Jordan, 2001; this study) and, to a much lesser degree, endozoochory (Carlquist, 1974; this study; Bramwell, 1985). All of the above suggest that non-standard dispersal events are more important for island colonization than previously believed, and their relevance for biogeography is not merely anecdotal (Nathan et al., 2008; Nogales et al., 2012). Such nonstandard dispersal vectors may include the undifferentiated transport of all types of diaspores by animals, oceanic rafts, extreme atmospheric conditions or even by drifting icebergs after glaciations (Fig. 2), such as suggested by Darwin (1859) to account for the presence of northern European species in the Azores. The apparent weak link between diaspore traits and actual dispersal vectors makes it very difficult to predict the most important mechanisms at work during the colonization of remote islands by plants. This prediction is particularly difficult for plants with unspecialized diaspores, which leads us to argue that the highly speculative exercise of inferring the most likely dispersal vectors of plants to remote archipelagos should be discouraged, as should the classification of fuzzy dispersal syndromes such as 'mud adherence' (see Nogales et al., 2012). An important clarification is that the current approach does not argue against the likely importance of birds (or any other vector) for the colonization of the Azores (Guppy, 1917; Dias et al., 2007; Schaefer et al., 2011a) but against the idea that adaptations towards a specific dispersal mode (birds or other) absolutely determine actual dispersal.

We believe that the comparison of syndrome frequency distributions adopted here is a more objective exercise as it does not require the assumption of a causal link between traits and dispersal vectors, and does not coerce unspecialized diaspores into ambiguous dispersal syndromes (Fig. 2) (Jordan, 2001; Higgins et al., 2003; Vargas et al., 2012). Instead, comparative analyses of LDD syndrome distributions provide a general framework to test explicit evolutionary hypotheses about dispersal mechanisms that are potentially important for island colonization within the theory of island biogeography.

One of the predictions of the theory of island biogeography is that differential dispersal potential across plant lineages can promote disharmonic species assemblages in oceanic islands (Carlquist, 1966; Macarthur \& Wilson, 1967; Whittaker et al., 1997). Indeed, we found that the Azorean flora does not comprise a perfectly harmonious subset of the European flora. We found an overrepresentation of Cyperaceae, Juncaceae and Potamogetonaceae, families in which thalassochorous diaspores are relatively common, and an underrepresentation of Asteraceae, a family largely characterized by anemochorous diaspores, and Fabaceae, a family mostly unspecialized regarding LDD syndromes (in Europe). These results strongly support a causal relationship between differential dispersibility associated with diaspore morphology and taxonomic disharmony.

\section{Limitations and future work}

The arrival of propagules to a new area sets the template for the next steps in the complex process of colonization. The comparison between the floras of the Azores and mainland Portugal tries to minimize the problem of potential lack of suitable habitat for establishment of European species. Mainland Portugal spans the same latitudinal range as the Azores $\left(37^{\circ} \mathrm{N}-41^{\circ} \mathrm{N}\right)$, has a similar elevational range (maximum elevation in the Azores is c. $2350 \mathrm{~m}$ and on the mainland $c$. $2000 \mathrm{~m}$ ) and has a comparable coastal length (Azores c. $670 \mathrm{~km}$, mainland c. $940 \mathrm{~km}$ ), all factors that can independently affect syndrome frequency distribution (Guppy, 1917; Moles et al., 2007). The strong alignment of the results from both comparisons (Europe-Azores and Portugal-Azores), attests to the robustness of our main conclusions. Future comparisons applying this approach to other regions will continue to shed light on the relative importance of dispersal and establishment.

We envisage that as more specific data become available the approach outlined here can be improved by including three sources of information. First, phylogenetic and phylogeographic corrections may improve the estimation of the number of colonization events and relative colonization success across species and families (Vargas et al., 2012). Secondly, information relative to the other critical steps of colonization and persistence on islands can be incorporated, and more importantly detailed habitat suitability models (e.g. niche modelling) can be developed to assess establishment limitations (Elith \& Leathwick, 2009; Aranda et al., 2013) and determine the roles of mutualistic and antagonistic species interactions on species persistence (Traveset et al., 2014). Finally, the patterns may be better resolved using further clarification of dispersal syndromes, particularly those that cannot be easily inferred from morphological traits alone (e.g. seed viability after ingestion and immersion in saltwater) (Thorsen et al., 2009). Nevertheless, the deep knowledge gained from the European flora over centuries coupled with the exhaustive assignation of syndromes to over 10,000 species, reinforces the robustness of the main results.

\section{Conclusion}

Our results suggest that dispersal by oceanic currents has significantly favoured the colonization of the Azores by plants, while wind dispersal was negatively favoured and endozoochory 
was possibly slightly favoured. The presence of epizoochorous traits did not seem to have any relevant effect on plant colonization success. Remarkably, the distribution of plants within the archipelago seems largely independent of specializations related to LDD, except for the slightly positive effect endozoochorous traits. This leads us to advocate a more prominent role for nonstandard dispersal events in island colonization than previously thought. Future work, in particular phylogeographic reconstructions, ecological niche modelling and seed survival tests, will further improve our understanding of how islands become green.

\section{ACKNOWLEDGEMENTS}

We are grateful to those who compiled and shared information about both floras and diaspore dispersal syndromes, especially to Paulo Borges, Hanno Schaeffer, Henry Ford, Martin Winter and all the colleagues who discussed different points of this study, particularly at the INTECOL (London 2013) and Island Biology (Honolulu 2014) conferences. We are also grateful to Pedro Jordano and Conley McMullen for their comments on the manuscript and Manuel Nogales, Jens Olesen and Anna Traveset for all the fruitful discussions. The following botanical experts were consulted: Juan Jose Aldasoro (Geraniaceae), Inés Alvarez (Asteraceae-Anthemideae), Pilar Catalán (Festuca), Modesto Luceño (Cyperaceae), Ana Ortega (Galium), Enrique Rico (Asteraceae-Gnaphalieae), Riki Riina (Euphorbiaceae). R.H. was funded by Fundação para Ciência e Tecnologia (IF/00441/ 2013) and by the Marie Curie Action (FP7-PEOPLE-2012-CIG321794), P.V. was funded by the Spanish Ministry of Economy and Competitiveness (CGL2012-38624-C02-01).

\section{REFERENCES}

Aranda, S.C., Gabriel, R., Borges, P.A.V., Santos, A.M.C., Hortal, J., Baselga, A. \& Lobo, J.M. (2013) How do different dispersal modes shape the species-area relationship? Evidence for between-group coherence in the Macaronesian flora. Global Ecology and Biogeography, 22, 483-493.

Azevedo, J.M.M. \& Ferreira, M.R.P. (2006) The volcanotectonic evolution of Flores Island, Azores (Portugal). Journal of Volcanology and Geothermal Research, 156, 90-102.

Barrón, E., Rivas-Carballo, R., Postigo-Mijarra, J.M., Alcalde-Olivares, C., Vieira, M., Castro, L., Pais, J. \& Valle-Hernández, M. (2010) The Cenozoic vegetation of the Iberian Peninsula: a synthesis. Review of Palaeobotany and Palynology, 162, 382-402.

Bramwell, D. (1985) Contribucion a la biogeografia de las islas Canarias. Botanica Macaronesica, 14, 3-34.

Carlquist, S. (1966) The biota of long-distance dispersal. I. principles of dispersal and evolution. Quarterly Review of Biology, 41, 247-270.

Carlquist, S. (1974) Island biology. Columbia University Press, Columbia.

Chesson, J. (1978) Measuring preference in selective predation. Ecology, 59, 211-215.
Climaat (2013) Project CIMAAT \& CLIMARCOST, Interreg IIIB. Available at: http://www.climaat.angra.uac.pt (accessed 16 October 2013).

Connor, S.E., Leeuwen, J.F.N.V., Rittenour, T.M., Knaap, W.O.V.D., Ammann, B. \& Bjorck, S. (2012) The ecological impact of oceanic island colonization - a palaeoecological perspective from the Azores. Journal of Biogeography, 39, 1007-1023.

Darwin, C. (1859) On the origin of species by means of natural selection, or the preservation of favoured races in the struggle for life. John Murray, London.

Dias, E. (2001) Ecologia e classificação da vegetação natural dos Açores. Departamento de Ciências Agrárias, Angra do Heroísmo, Açores.

Dias, E., Elias, R., Melo, C. \& Mendes, C. (2007) Biologia e ecologia das florestas das Ilhas - Açores. Açores e Madeira: a floresta das Ilhas (ed. by J.S. Silva), pp. 51-80. Publico, Fundação Luso-Americana, Lisbon.

Elith, J. \& Leathwick, J.R. (2009) Species distribution models: ecological explanation and prediction across space and time. Annual Review of Ecology, Evolution, and Systematics, 40, 677697.

Fernandez-Palacios, J.M., De Nascimento, L., Otto, R., Delgado, J.D., Garcia-Del-Rey, E., Arevalo, J.R. \& Whittaker, R.J. (2011) A reconstruction of Palaeo-Macaronesia, with particular reference to the long-term biogeography of the Atlantic island laurel forests. Journal of Biogeography, 38, 226-246.

Gillespie, R.G. (2007) Oceanic islands: models of diversity. Encyclopedia of biodiversity (ed. by S. Levin), pp. 1-13. Elsevier, New York.

Gillespie, R.G., Baldwin, B.G., Waters, J.M., Fraser, C.I., Nikula, R. \& Roderick, G.K. (2012) Long-distance dispersal: a framework for hypothesis testing. Trends in Ecology and Evolution, 27, 52-61.

Godman, F.D.C. (1870) Natural history of the Azores or Western Islands. John van Voorst, London.

Guppy, H.B. (1917) Plants, seeds, and currents in the West Indies and Azores: the results of investigations carried out in those regions between 1906 and 1914. Williams and Norgate, London.

Heleno, R.H., Ross, G., Everard, A., Ramos, J.A. \& Memmott, J. (2011) On the role of avian seed predators as seed dispersers. Ibis, 153, 199-203.

Heleno, R., Olesen, J.M., Nogales, M., Vargas, P. \& Traveset, A. (2013) Seed-dispersal networks in the Galápagos and the consequences of plant invasions. Proceedings of the Royal Society B: Biological Sciences, 280, 20122112.

Higgins, S.I., Nathan, R. \& Cain, M.L. (2003) Are longdistance dispersal events in plants usually caused by nonstandard means of dispersal? Ecology, 84, 1945-1956.

Howe, H.F. \& Smallwood, J. (1982) Ecology of seed dispersal. Annual Review of Ecology and Systematics, 13, 201-228.

Hughes, L., Dunlop, M., French, K., Leishman, M.R., Rice, B., Rodgerson, L. \& Westoby, M. (1994) Predicting dispersal spectra: a minimal set of hypotheses based on plant attributes. Journal of Ecology, 82, 933-950. 
Jordan, G.J. (2001) An investigation of long-distance dispersal based on species native to both Tasmania and New Zealand. Australian Journal of Botany, 49, 333-340.

Macarthur, R. \& Wilson, E. (1967) The theory of island biogeography. Princeton University Press, Princeton.

Meireles, R.P., Quartau, R., Ramalho, R.S., Rebelo, A.C., Madeira, J., Zanon, V. \& Ávila, S.P. (2013) Depositional processes on oceanic island shelves-Evidence from stormgenerated Neogene deposits from the mid-North Atlantic. Sedimentology, 60, 1769-1785.

Mittlebach, G.G. (2000) Fish foraging and habitat choice: a theoretical perspective. Handbook of fish biology and fisheries (ed. by P.B. Hart and J.D. Reynolds), pp. 251-266. Blackwell Publishing, Malden, MA.

Moles, A.T., Ackerly, D.D., Tweddle, J.C., Dickie, J.B., Smith, R., Leishman, M.R., Mayfield, M.M., Pitman, A., Wood, J.T. \& Westoby, M. (2007) Global patterns in seed size. Global Ecology and Biogeography, 16, 109-116.

Nathan, R. (2006) Long-distance dispersal of plants. Science, 313, 786-788.

Nathan, R., Schurr, F.M., Spiegel, O., Steinitz, O., Trakhtenbrot, A. \& Tsoar, A. (2008) Mechanisms of long-distance seed dispersal. Trends in Ecology and Evolution, 23, 638647.

Nogales, M., Heleno, R., Traveset, A. \& Vargas, P. (2012) Evidence for overlooked mechanisms of long-distance seed dispersal to and between oceanic islands. New Phytologist, 194, 313-317.

Panero, J.L., Francisco-Ortega, J., Jansen, R.K. \& Santos-Guerra, A. (1999) Molecular evidence for multiple origins of woodiness and a New Would biogeographic connection of the Macaronesian island endemic Pericallis (Asteraceae : Senecioneae). Proceedings of the National Academy of Sciences USA, 96, 13886-13891.

Ridley, H.N. (1930) The dispersal of plants throughout the world. L. Reeve \& Co., Kent.

Schaefer, H. (2003) Chorology and diversity of the Azorean flora. Dissertationes botanicae, vol. 374. J. Cramer, Stuttgart.

Schaefer, H., Hardy, O.J., Silva, L., Barraclough, T.G. \& Savolainen, V. (2011a) Testing Darwin's naturalization hypothesis in the Azores. Ecology Letters, 14, 389396.

Schaefer, H., Moura, M., Maciel, M.G.B., Silva, L., Rumsey, F.J. \& Carine, M.A. (2011b) The Linnean shortfall in oceanic island biogeography: a case study in the Azores. Journal of Biogeography, 38, 1345-1355.

Silva, L., Land, E.O. \& Luengo, J.R. (2008) Invasive terrestrial flora \& fauna of Macaronesia. TOP 100 in Azores, Madeira and Canaries, edn. ARENA, Ponta Delgada.

Thomson, F.J., Moles, A.T., Auld, T.D., Ramp, D., Ren, S.Q. \& Kingsford, R.T. (2010) Chasing the unknown: predicting seed dispersal mechanisms from plant traits. Journal of Ecology, 98, 1310-1318.

Thorsen, M.J., Dickinson, K.J.M. \& Seddon, P.J. (2009) Seed dispersal systems in the New Zealand flora. Perspectives in Plant Ecology, Evolution and Systematics, 11, 285-309.
Traveset, A., Heleno, R.H. \& Nogales, M. (2014) The ecology of seed dispersal. Seeds: the ecology of regeneration in plant communities (ed. by R.S. Gallagher), pp. 62-93. CABI, Wallingford.

Tutin, T.G., Heywood, V.H., Burges, N.A. \& Moore, D.M. (1980) Flora Europaea (vols $I-V$ ). Cambridge University Press, Cambridge.

Van Der Pijl, L. (1982) Principles of dispersal in higher plants. Springer-Verlag, Berlin.

Vargas, P. (2007) Are Macaronesian islands refugia of relict plant lineages? : a molecular survey. Phylogeography in southern European refugia: evolutionary perspectives on the origins and conservation of European biodiversity (ed. by S.J. Weiss and N. Ferrand), pp. 297-314. Springer Netherlands, Dordrecht, The Netherlands.

Vargas, P., Heleno, R., Traveset, A. \& Nogales, M. (2012) Colonization of the Galápagos Islands by plants with no specific syndromes for long-distance dispersal: a new perspective. Ecography, 35, 33-43.

Vargas, P., Nogales, M., Jaramillo, P., Olesen, J., Traveset, A. \& Heleno, R. (2014) Plant colonization across the Galápagos Islands: success of the sea dispersal syndrome. Botanical Journal of the Linnean Society, 174, 349-358.

Whittaker, R.J. \& Fernández-Palacios, J.M. (2007) Island biogeography: ecology, evolution, and conservation. Oxford University Press, Oxford.

Whittaker, R.J., Bush, M.B. \& Richards, K. (1989) Plant recolonization and vegetation succession on the Krakatau Islands, Indonesia. Ecological Monographs, 59, 59-123.

Whittaker, R.J., Jones, S.H. \& Partomihardjo, T. (1997) The rebuilding of an isolated rain forest assemblage: how disharmonic is the flora of Krakatau? Biodiversity and Conservation, 6, 1671-1696.

Winter, M., Schweiger, O., Klotz, S., Nentwig, W., Andriopoulos, P., Arianoutsou, M., Basnou, C., Delipetrou, P., Didžiulis, V., Hejda, M., Hulme, P.E., Lambdon, P.W., Pergl, J., Pyšek, P., Roy, D.B. \& Kühn, I. (2009) Plant extinctions and introductions lead to phylogenetic and taxonomic homogenization of the European flora. Proceedings of the National Academy of Sciences USA, 106, 21721-21725.

Additional references to the data sources used in the study can be found at the end of Appendix S6 in the Supporting Information.

\section{SUPPORTING INFORMATION}

Additional supporting information may be found in the online version of this article at the publisher's web-site.

Appendix S1 A step-by-step guide for the characterization of long-distance dispersal syndromes.

Appendix S2 Characterization of the long-distance dispersal syndromes of the Azorean flora.

Appendix S3 Expected and observed syndrome frequency distributions for the Azores. 
Appendix S4 Frequency distribution of long-distance dispersal syndromes across the nine Azorean islands.

Appendix S5 Distribution of the Azorean native plant species across the archipelago.

Appendix S6 Disharmonic species richness across European and Azorean plant families.

\section{BIOSKETCHES}

Ruben Heleno is a young researcher mostly interested in seed dispersal, pollination and other ecological networks and their interfaces with island biogeography, conservation and restoration science. He has conducted and led research in the Azores, Galápagos and in Gorongosa, Mozambique.

Pablo Vargas is a senior scientist leading projects on the evolution and molecular systematics of Mediterranean plants, and interested in the biogeography, colonization, phylogenetics, speciation and evolution of the floras of Macaronesia, Galápagos and Hawaii.

Author contributions: both authors planned and discussed the study, P.V. assembled the dataset and coded species dispersal syndromes and R.H. did the analyses and led the writing.

Editor: Greg Jordan 